Historically, multi-infarct dementia (MID) has been the only alternative to primary degenerative dementia, and most of the diagnostic scales, neuropsychological tests, and neuroimaging studies have been directed to this condition, the result being the ignorance of the prevalence of other subtypes of $\mathrm{VaD}$. A classification of $\mathrm{VaD}$ should also include cases of dementia resulting from both ischaemic and haemorrhagic lesions in the brain, and from cerebral ischaemic-hypoxic lesions due to haemodynamic abnormalities as well (Serra-Mestres \& LópezPousa, 1992; Román, 1993).

The Hachinski Ischaemic Scale has turned out to be a misleading instrument. A recent prospective neuropathological study to validate this scale found that $21 \%$ of patients with Alzheimer-type dementia (ATD) were incorrectly diagnosed as having VaD. It also has been reported to be insensitive in the detection of mixed cases of dementia.

The nature of cerebrovascular disease makes it difficult to define patterns of cognitive impairment. It has been suggested that for epidemiological purposes, a high-sensitivity screening instrument should be used (Román, 1993)

At the pathological level, the introduction of haemorrhagic and haemodynamic lesions in the spectrum of $\mathrm{VaD}$ is a success, but the argument on what size and/or volume and localisation of the lesions is required to produce cognitive impairment, still continues. It has been postulated (Garcia et al, 1992) that there are critical areas of the brain which are implicated in the production of cognitive failure: associative areas of the posterior-caudal half of the cortex, inferomesial parts of the temporal lobes, superior regions of parietal and frontal lobes, subcortical white matter (especially corona radiata), thalamus, basal ganglia, and diencephalic structures. The role of the white matter lesions in cognitive dysfunction is controversial.

Neuroimaging techniques have to be considered. Lack of vascular lesions in computerised tomographic scans or magnetic resonance images (MRI) is strong evidence against a vascular aetiology. The use of MRI is strongly recommended because of its higher power of resolution, especially of subcortical structures.

Attempts to design diagnostic criteria for $\mathrm{VaD}$ have been made (ICD-10; Chui et al, 1992). Recently the NINDS-AIREN Diagnostic Criteria for Research Studies in Vascular Dementia have been published (Román, 1993). Their authors emphasise the need for clinical, radiological and pathological data to arrive at the diagnosis of $\mathrm{VaD}$. It is urgent that these criteria be used at clinical and research levels. Correlation studies will then be needed to test their validity.
Chü, H. C., Victoroff, J. I., Margolnn, D., el al (1992) Criteria for the diagnosis of ischemic vascular dementia proposed by the state of California Alzheimer's Disease Diagnostic and Treatment Centers. Neurology, 42, 473-480.

Garcin, J. H., Brown, G. G. \& Helpern, J. A. (1992) The neuropathological substrate of vascular dementia: a working hypothesis. In Vascular dementia: Proceedings of the NINDS-AIREN International Workshop on Vascular Dementia (ed. G. C. Román). NIH, Bethesda, MD, 1991. New issues in Neurosciences, 4.

Romín, G. C. (1993) Vascular dementia: diagmostic criteria for research studies. Report of the NINDS-AIREN International Workshop. Neurology, 43, 250-260.

Serra-Mestres, J. \& López-Pousa, S. (1992) Propuesta de clasificación y protocolo de estudio de las demencias de etiologia vascular. In Epidemilogía de la Demencia Vascular: Controversias en su Diagnóstico. (eds S. López-Pousa, J. M. Manubens \& W. A. Rocca), pp. 105-128. Barcelona: JR Prous.

\section{Hinchingbrooke Hospital}

Huntingdon

Cambridgeshire PE18 8NT

\section{Offspring of parents with drinking problems}

SIR: The comprehensive study about the adult adjustment of offspring of parents with drinking problems by Velleman \& Orford (Journal, April 1993, 162, 503-516) concludes that having a parent with a drinking problem might sometimes be a strengthening experience, contrary to previous reports. Recently, Michael et al (1993) reported higher interhemispheric electroencephalogram (EEG) scores in teetotaller, first-degree relatives of alcoholics compared with both alcoholics and minimal, social drinkers. They argued that this might represent protective factors - for example high arousal, high vigilance, and so on - which prevented them from becoming alcoholics themselves. Unfortunately, in the present study, the offspring of alcoholics were regarded as a homogenous group. In view of the EEG findings it seems that if the offspring of alcoholics in the present study were subgrouped into social drinkers and teetotallers they would have had a greater chance of getting more robust findings to support their case.

Michael, A., Mirza, K. A. H., Mukundan, C. R., et al (1993) Inter hemispheric EEG coherence as a biological marker in alcoholism. Acta Psychiatrica Scandinavica, 87, 213-217.

North Wales Hospital

A. Fernandez

Denbigh, LL16 5SS

\section{Münchhausen's syndrome?}

SIR: Fisher et al (Journal, May 1993, 162, 701-703) report a case of a so-called Munchausen's syndrome by proxy. It was the Baron Karl Friedrich Hieronymus 
von Münchhausen (1720-1797, Bodenwerder, Germany), called the lying baron (Lügenbaron), whose name has been given to this syndrome. The Baron himself would smile at reading his name 'Munchausen' in the English literature, mutilated as it is (the meaning being 'house of the monk'). But I think he deserves nevertheless a correct citing of his name, he who during his lifetime was not a decided fan of truth.

Arzt für Neurologie und Psychiatrie

REINHARD ODY

Leitender Abteilungsarzt Psychomedizinische

Abteilung

Marien-Hospital Euskirchen

\section{Community Treatment Orders}

SIR: I wish to echo Dr Hardman's recommendation (Journal, May 1993, 162, 710) that scrutiny of the Victorian Community Treatment Order (CTO) system be made in order that its applicability in England be clarified. I agree that the CTO is not used a great deal - the service in which I work has a catchment population of 210000 and geographically covers $20 \%$ of the State, but has only 31 such Orders at the time of writing. It is the experience of most of our community psychiatric nurses that the CTO is indeed useful as a 'persuader' where depot neuroleptics are concerned, and this service has also found it useful in the placement of longer stay, institutionalised individuals into a community residential programme.

The actual practical usefulness of the CTO when its role as a persuader is insufficient - that is, when a person is, for example, still refusing his/her medication - is a more difficult issue. The main legal redress offered in these circumstances is revokation or return to hospital as an involuntary patient.

While there is nothing in the law to prevent an injection being given by force in a patient's own home, the practical reality is that most nurses are reluctant to do this, given its potential personal risk and the chances of significant damage to the therapeutic relationship. In practice, then, the CTO is revoked for a period of time long enough to remove the patient to hospital, to give the injection, and to return the patient home. While this is cumbersome in terms of paperwork, it does at least assure us that adequate treatment will be delivered, and is practically a far better arrangement than the English Guardianship Order, which can direct a patient to attend for treatment but places no onus on the patient to take it.

The CTO is, of course, no substitute for adequate patient and carer education and appropriate compliance training. Rather, it is an augmentation to other more clinically-based concepts of care in the community, as, indeed, is any aspect of the Mental Health Act. In support of Professor Lamb's (Journal, May 1993, 162, 587-592) assertion that "the chronically mentally ill ... need asylum and sanctuary in the community", a CTO is likely to ensure they have treatment as well.

\section{Hobson Park Hospital \\ Hazelwood Road \\ Traralgon, Victoria}

Graham RidLey

\section{Mania and Down's syndrome}

SIR: Drs Cooper \& Collacott (Journal, June 1993, $162,739-743)$ are incorrect in stating "There have been no reported cases of mania in women with Down's syndrome". Haeger (Journal, July 1990, 157, 153) reported a case of recurrent mania in a 46-yearold woman; her first episode occurring at the age of 32 years. Table 1 requires amending to include this case.

If the case reported by Haeger is incorporated with those reviewed by the above authors, there have then been eight reported cases of mania in people with Down's syndrome, seven male and one female, the mean age of first manic episode is corrected to 33.4 years, and the length of follow-up from first episode to time of report becomes $1-14$ years.

Subsequent amendments of symptom frequency (Table 2) include an increase by a factor of one of elated mood, pressure of speech, sleeplessness, sexual inhibition, physical aggression, and possibly grandiose ideas. Long-term prophylaxis was addressed using maintenance promazine.

The author recommends that all review articles state their source of reference information, thereby allowing an assessment of the accuracy of the data collection to be made and prevention of subsequent publication of inaccurate information.

University of Birmingham

V. P. Prasher

Birmingham B15 $2 Q Z$

\section{Low serum cholesterol and serotonin receptor} subtypes

SIR: We read with interest the article by Hawton et al about low serum cholesterol and suicide (Journal, June 1993, 162, 818-825). One of the main concerns of the authors is the lack of available in vivo data about the effects of low serum cholesterol on serotonin receptor subtypes which are especially involved 